\title{
The Association of Health Literacy Level with Self-Care Behaviors and Glycemic Control in a Low Education Population with Type 2 Diabetes Mellitus: A Cross-Sectional Study in Iran
}

This article was published in the following Dove Press journal:

Diabetes, Metabolic Syndrome and Obesity: Targets and Therapy

\section{Khalil Maleki Chollou' Saber Gaffari-fam (iD) ${ }^{2}$ \\ Towhid Babazadeh (1D ${ }^{3}$ \\ Amin Daemi ${ }^{4}$ \\ Ali Bahadori ${ }^{5}$ \\ Sohrab Heidari ${ }^{2}$}

'Department of Nursing, Sarab Faculty of Medical Sciences, Sarab, Iran; ${ }^{2}$ School of Nursing of Miandoab City, Urmia University of Medical Sciences, Urmia, Iran; ${ }^{3}$ Department of Public Health, Sarab Faculty of Medical Sciences, Sarab, Iran; ${ }^{4}$ Health Management and Economics Research Center, Iran University of Medical Sciences, Tehran, Iran; ${ }^{5}$ Food and Drug Safety Research Center, Tabriz University of Medical Science, Tabriz, Iran
Correspondence: Towhid Babazadeh Department of Public Health, Sarab Faculty of Medical Sciences, Sarab, Iran Tel +98 4I 43224586

Fax +984143237412

Email towhid.babazadeh@gmal.com
Introduction: Promoting Health Literacy (HL) can be a priority in strategic healthcare planning of the countries. Low HL is prevalent in some societies which make barriers to successful self-care of diseases. The aim of this study was to examine the association of HL with self-care behaviors and glycemic control in a low education population with type 2 diabetes mellitus.

Methods: This cross-sectional study was conducted in Sarab city, Iran. The 192 participants were patients diagnosed as type 2 diabetes and with low level of education. Convenient sampling method was applied and the participants were chosen by their medical records in health-care centers. To collect data a valid and reliable tool was used based on HL dimensions and self-care behaviors. Using hierarchical logistic regression, the possible association of variables with self-care behaviors and glycemic control was assessed.

Results: The mean age of study participants was $58.12( \pm 11.83)$ years. A $28.8 \%$ of the variation in the self-care behaviors is explained by the HL and the demographic variables $(\mathrm{R}=0.288 \%$; $\mathrm{p}$-value $<0.05)$. Furthermore, decision-making was the strongest predictor of self-care behaviors $(\beta=0.451)$. Approximately $80 \%$ of the variation in the HbA1c is explained by the HL, self-care behaviors, and the demographic variables $(\mathrm{R}=0.804 \%$; p-value $<0.05)$.

Conclusion: This study revealed that the HL dimensions predicted approximately onefourth of self-care behaviors and the self-care behaviors and HL dimensions about eighttenths of $\mathrm{HbAlc}$ in this population. These findings call for the need for interventional programs on HL to improve the self-care behaviors and HbAlc control.

Keywords: health literacy, diabetes mellitus, hemoglobin A1c protein, self-care

\section{Introduction}

Type 2 diabetes mellitus (T2DM) has quickly became one of the world's most prevalent non-communicable diseases, and one of the most daunting problems in public health. ${ }^{1}$ According to the World Health Organization (WHO) report of 2016, there are approximately 422 million diabetic adults globally, ${ }^{2}$ and it is estimated that this number would reach 438 million in $2030 .{ }^{3}$ Based on the statistics reported by the studies, the overall prevalence of diabetes in the US is reported to be $10.5 \%$ in 2020. ${ }^{4}$ According to the estimates, the prevalence of diabetes in Iran was approximately 2 million people in 2005 and it will double by 2025 to $7.7 \%$. 
Diabetes caused $\sim 4$ million deaths in 2017 and cost people with diabetes over USD 727 billion, which is equal to $12.5 \%$ of the overall global health-care budget. $^{5}$

Achievement of targets such as glycemic control which includes fasting blood glucose and glycosylated hemoglobin $(\mathrm{HbA} 1 \mathrm{c})$ is recommended to reduce diabetes-related mortality and economic costs. ${ }^{6} \mathrm{HbAlc}$ is a key predictor of glycemic control. ${ }^{7}$ Lower levels of HbAlc have been correlated with decreased mortality among diabetic patients and less complications. ${ }^{8,9}$ Previous studies' findings recommend that self-care behaviors, ${ }^{10}$ increased diabetes knowledge, ${ }^{11}$ and greater medication adherence ${ }^{12}$ are related to better glycemic control. ${ }^{13}$ In several studies, it is found that the main determinant of regulated $\mathrm{HbAlc}$ is the better self-care behaviors. ${ }^{14,15}$

Self-care for diabetes includes healthy diet, regular exercise, adherence to the medical treatment system, blood glucose regulation and tracking, as well as skills to promote health. ${ }^{16}$ Many factors affecting T2DM patients' self-care behaviors have been reported to include socioeconomic positions, awareness of diabetes, health beliefs, attitude, motivation, social support ${ }^{17,18}$ and the HL. ${ }^{19}$

Based on definition by the WHO, HL is

The cognitive and social skills which determine the motivation and ability of individuals to gain access to, understand and use information in ways which promote and maintain good health. ${ }^{20}$

HL can facilitate the self-management of $\mathrm{T} 2 \mathrm{DM},{ }^{21}$ positive involvement in diabetes treatment and interactive communication with health professionals. ${ }^{22}$ Patients with low HL have difficulty in reading medication labels, understanding dosage instructions, using health-related information brochures, providing their informed consents, and interpreting medical test results. ${ }^{23}$ Low HL also leads to inadequate knowledge of health records, directions, and less engagement of the patients in preventive measures. All these can lead to a late diagnosis of one's condition. $^{24,25}$

Inadequate HL is independently related to poor glycemic regulation, low medication adherence and higher retinopathy rates. ${ }^{26}$ More specifically, T2DM patients with high levels of HL are more likely to face with diabetes self-care problems compared to those with low HL. ${ }^{27}$

Schillinger et $\mathrm{al}^{26}$ found that insufficient $\mathrm{HL}$ was related to poor glycemic control and higher rates of retinopathy, whereas Morris et $\mathrm{al}^{28}$ found that HL was not correlated with HbAlc, blood pressure, or lipid levels.
Powell et al reported that low HL levels in patients with T2DM have been associated with poor HbA1c and poor diabetes knowledge. ${ }^{27}$ Also, a systematic review study found a relationship between $\mathrm{HL}$ and HbA1c. ${ }^{29}$ Some studies showed that a high level of HL had been correlated with better HbA1c. ${ }^{30}$ In addition, other studies showed that HL had an indirect impact on HbAlc, and that there was not a direct relationship between them. ${ }^{31,32}$

Understanding the process of relationships between $\mathrm{HL}$, self-care behaviors, and $\mathrm{HbA} 1 \mathrm{c}$ could provide useful knowledge to improve evidence-based interventions in diabetes patients. The purpose of this study was to examine the association of HL with self-care behaviors and the glycemic control in a low education population with T2DM. We hypothesized that HL in this population would be separately associated with self-care behaviors and glycemic control.

\section{Methods}

\section{Study Area and Study Design}

The current cross-sectional study was conducted in Sarab city, East Azerbaijan province, northwest of Iran. This 5-month study took place from September 2019 to February 2020. Based on the $t$-test exam from the test family, and from the "correlation: point biserial model" in the statistical test, in the G*Power software the input parameters were two tail hypothesis, effect size $=0.245$, $\alpha$ error probability $=0.05$, power $(1-\beta$ error probability $=$ $0.95)$, respectively. Sample sized calculated to be $205^{33}$ of which 192 agreed to participate in the study (Response rate $=93.7 \%$ ).

According to the Iranian health system, the health information of all residents is documented in the health centers. Therefore, information from the health centers records were obtained and convenient sampling method was applied to select the participants. After stating study goals and obtaining informed consent from the study participants, face to face interview was used by the trained interviewers to complete the questionnaires. The interviews lasted 20 to 25 minutes.

Inclusion criteria were having a medical record as a T2DM patients in the health centers of Sarab city, being aged $\geq 30$ years, controlled or uncontrolled diabetes, with or without complications, and having low education (secondary school and less). Exclusion criteria included having psychotic disorder, dementia, blindness, and refusal to participate in the study. 


\section{Ethical Consideration}

The study protocol was approved by the Sarab Faculty of Medical Sciences Institutional Review Board. Each participant was given an oral description of the study and signed a consent form prior to attendance.

\section{Measurement}

The self-administered anonymous questionnaires including demographic characteristics, HL questionnaire, and selfcare questionnaire were used to collect data.

\section{Demographic Characteristics}

The covariates in the models were sociodemographic characteristics which were also collected in the survey as well, including age (years), sex, job (employed, unemployed, and housewife), and marital status (single, married).

\section{$\mathrm{HL}$}

The independent variable of the study was the HL, which was assessed by a valid and reliable instrument that was developed by Montazeri et al to assess HL among Iranian adults. ${ }^{34}$ Briefly, this tool is composed of five subscales with 34 items and the Cronbach's alpha coefficient between 0.72 and 0.89 . Details of the HL instrument are described as follows:

\section{Reading Health Information}

Reading health information was assessed by a four-item subscale on a five-point Likert-type scale ranging from 1 to 5 ( $1=$ completely difficult through $5=$ completely easy). An example of this dimension was: "reading health education materials (booklet, pamphlet, and educational brochures) was easy for me". Cronbach's alpha for this subscale was estimated at 0.72 . The total possible scores ranged from 4 to 20 , higher the score, the greater the reading abilities.

\section{Understanding Health Information}

Seven items were used to measure understanding health information (e.g., "I can acquire the required health and medical information from different sources"). Each item was rated on a 5-point scale from 1 to 5 (1= completely difficult through $5=$ completely easy). Cronbach's alpha for this subscale was 0.86 . For this subscale, theoretical range was $7-35$, the higher the scores, the more ability to understand health information.

\section{Appraisal of Health Information}

Appraisal of health information was measured by applying four items (eg, "I can get information about healthy nutrition"). Each item was rated on a five-point Likert-type scale that ranged from 1 (never) to 5 (always). Cronbach's alpha for this subscale was 0.77 . The total possible score on this index could range from 4 to 20. A high total score showed a high level of appraisal of health information.

\section{Ability to Access Health Information}

This subscale was assessed by six items (e.g., "I can obtain information about my illness"). A five-point Likert-type scale was used (always $=5$, most of the time $=4$, sometimes $=3$, seldom $=2$ and never $=1$ ). Cronbach's alpha for this subscale was 0.86 . The total possible scores ranged from 6 to 30 in which the higher the score, the more ability to access health information.

\section{Decision Making}

Decision making was a twelve-item subscale that was developed to measure the ability to decide health-related behaviors. Sample of items is: "I avoid doing things or taking materials that might increase my weight" even if the symptoms of the disease would be disappeared. The items were rated on a five-point Likert-type scale ranging from 1 to 5 (always $=5$, most of the time $=4$, sometimes $=$ 3 , seldom $=2$ and never $=1$ ). Cronbach's alpha for this subscale was 0.89 . The higher the score, the better decision making was concluded.

\section{Diabetes Self-Care Behavior}

Self-care behavior was assessed with the 12-item summary of diabetes self-care activities scale, ${ }^{35}$ which had been validated and its reliability was verified by Didarloo et al, in Iran. ${ }^{36}$ The instrument measures frequency of selfcare behaviors in the last 7 days for four parts of: diet (6 items), glucose monitoring ( 2 items), medications (2 items) and exercise ( 2 items). The Cronbach's alpha was estimated at 0.74 for this instrument. The total possible score on this index may range from 0 to 84 in which higher scores indicated the higher self-care behaviors adopted by the patients.

\section{Glycemic Control}

The outcome variable was patients' most recent $\mathrm{HbA1c}$ value; the new $\mathrm{HbA} 1 \mathrm{c}$ value was derived from the medical record for patients and used as a glycemic control measure. The level of glycemic control was categorized with $7 \%$ HbA1C according to The American Diabetes Association (ADA) Standards of Medical Care in Diabetes. $^{37}$ 


\section{Data Analysis Procedure}

Data were analyzed using the Statistical Package for Social Sciences (SPSS) version 21 (SPSS, Inc., Chicago, IL). The quantitative characteristics of the participants were described using mean, standard deviation and the qualitative ones with frequency (percent). The Pearson correlation coefficient was used to quantify the linear relationship between HL score and self-care behaviors and the HbA1c. Researchers often want to check theoretical hypothesis and examining sequentially at the effect of several predictor variables, so that the relative important of a predictive can be measured on the basis of how much it contributes to the estimation of a criterion, beyond what other important predictors may account for. A common goal in stepwise and simultaneous regression, a common focus is to determine the "optimal" set of predictors by limiting the number of predictors without reducing the R2 coefficient significantly. Nevertheless, in hierarchical regression the emphasis is on the change in predictability correlated with later entered predictor variables in the analysis above and beyond that caused by predictor variables entered in the analysis earlier. In our study, we wanted to know the extent to which measures of positive expectations about HL predict the self-care behavior outcome. The socioeconomic variables were entered into the analysis first, followed by positive expectations about selfcare behaviors and then HL constructs were entered into the analysis to determine whether newly added variables show a significant improvement in R2 (the proportion of explained variance in dependent variable by the model).

Using the enter approach, a hierarchical logistic regression analysis was applied in two steps. The first model
(Model 1) typically included demographic information such as age, sex, job, and marital status. In the next step (Model 2), we added the HL and the self-care behaviors variables in this line of research. P-value of 0.05 or less determined as statistical significance in all analysis.

\section{Results}

The demographics variables of the participants are shown in Table 1. The mean age of subjects was $58.12 \pm 11.83$ years. Participants were mainly male $(55.2 \%, n=106)$ and married $(82.3 \%, n=158)$. Approximately $20 \%(n=38)$ of the participants were unemployed. No statistically significant difference was found in demographic variables by self-care behaviors. As it is displayed in Table 1, a statistically significant association was found in HL by the age of patients ( $p$-value $=0.002)$. The table demonstrates that the scores of HL was lower among unemployed people $(\mathrm{p}$-value $=0.001)$.

Table 2 presents the bivariate correlations for $\mathrm{HL}$ dimensions and self-care behaviors. Applying Pearson correlation coefficient test, we found that self-care behaviors had statistically significant correlations with all HL dimensions ( $p$-value $<0.05$ ) except for reading health information ( $p$-value $>0.05$ ).

Hierarchical multiple linear regressions were performed on HL dimensions and self-care behaviors, as the outcome variable. As there is presented in Table 3, in step 1 , demographic variables were not significant predictors of self-care behaviors ( $\mathrm{p}$-value $>0.05, \mathrm{R} 2$ total $=0.003$ ). In step 2, when the HL dimensions were included in the model, reading health information ( $\mathrm{p}$-value $=0.01$ ), appraisal of health information ( $\mathrm{p}$-value $=0.008)$, and decision-

Table I Demographic Characteristics of the Study Participant and Their Association with Self-Care Behaviors and HL

\begin{tabular}{|c|c|c|c|c|c|c|c|c|}
\hline \multicolumn{2}{|l|}{ Variables } & \multirow{3}{*}{$\begin{array}{l}\text { F (\%) } \\
53(27.6) \\
139(72.4)\end{array}$} & \multirow{3}{*}{$\begin{array}{l}\text { Self-Care Behaviors } \\
\text { Mean } \pm \text { SD } \\
43 \pm 10.17 \\
43.50 \pm 10.08\end{array}$} & \multirow{3}{*}{$\begin{array}{l}\text { p-value } \\
0.580\end{array}$} & \multirow{2}{*}{$\begin{array}{l}\text { HL } \\
\text { Mean } \pm \text { SD }\end{array}$} & \multirow[t]{3}{*}{ p-value } & \multirow{3}{*}{$\begin{array}{l}\text { HbAIC } \\
\text { Mean } \pm \text { SD } \\
7.27 \pm 1.11 \\
7.24 \pm 1.02\end{array}$} & \multirow{3}{*}{$\begin{array}{l}\text { p-value } \\
0.867\end{array}$} \\
\hline & & & & & & & & \\
\hline Age groups (years) * & $\begin{array}{l}50> \\
50 \leq\end{array}$ & & & & $\begin{array}{l}94.01 \pm 23.80 \\
83.85 \pm 18.64\end{array}$ & & & \\
\hline Gender * & $\begin{array}{l}\text { Male } \\
\text { Female }\end{array}$ & $\begin{array}{l}106(55.2) \\
86(44.8)\end{array}$ & $\begin{array}{l}43.88 \pm 10.17 \\
43.50 \pm 10.08\end{array}$ & 0.793 & $\begin{array}{l}88.84 \pm 22.79 \\
84.33 \pm 17.50\end{array}$ & 0.161 & $\begin{array}{l}7.21 \pm 1.05 \\
7.29 \pm 1.06\end{array}$ & 0.590 \\
\hline Job ** & $\begin{array}{l}\text { Employed } \\
\text { Unemployed } \\
\text { Housewife }\end{array}$ & $\begin{array}{l}77(40.1) \\
38(19.8) \\
77(40.1)\end{array}$ & $\begin{array}{l}44.20 \pm 9.49 \\
41.44 \pm 12.10 \\
44.33 \pm 9.60\end{array}$ & 0.305 & $\begin{array}{l}93.20 \pm 23.01 \\
79.39 \pm 20.98 \\
83.70 \pm 15.76\end{array}$ & 0.001 & $\begin{array}{l}7.18 \pm 1.07 \\
7.41 \pm 1.04 \\
7.23 \pm 1.03\end{array}$ & 0.542 \\
\hline Marital status * & $\begin{array}{l}\text { Married } \\
\text { Single }\end{array}$ & $\begin{array}{l}158(82.3) \\
34(17.7)\end{array}$ & $\begin{array}{l}43.77 \pm 10.41 \\
43.41 \pm 8.71\end{array}$ & 0.848 & $\begin{array}{l}87.25 \pm 19.99 \\
83.88 \pm 23.57\end{array}$ & 0.388 & $\begin{array}{l}7.25 \pm 1.07 \\
7.27 \pm 0.97\end{array}$ & 0.976 \\
\hline
\end{tabular}

Notes: ${ }^{*}$-value-based Independent T-test, **p-value-based one-way ANOVA test. 
Table 2 Bivariate Correlation Between HL Dimensions, Self-Care Behaviors and HbAlc

\begin{tabular}{|c|c|c|c|c|c|c|c|c|}
\hline Variables & $\mathbf{I}$ & 2 & 3 & 4 & 5 & 6 & 7 & Mean \pm SD \\
\hline $\mathrm{I}=$ Reading health information & I & & & & & & & $7.48 \pm 4.10$ \\
\hline $2=$ Ability to access health information & $0.688^{*}$ & I & & & & & & $15.02 \pm 5.35$ \\
\hline $3=$ Understanding health information & $0.725^{*}$ & $0.747^{*}$ & I & & & & & $17.98 \pm 5.11$ \\
\hline $4=$ Appraisal of health information & $0.618^{*}$ & $0.746^{*}$ & $0.680 *$ & I & & & & $10.51 \pm 3.08$ \\
\hline $5=$ Decision-making & $0.386 *$ & $0.732 *$ & $0.647^{*}$ & $0.520 *$ & 1 & & & $35.65 \pm 7.27$ \\
\hline $6=$ Self-care behaviors & 0.041 & $0.208^{*}$ & $0.244^{*}$ & $0.315^{*}$ & $0.46 I^{*}$ & I & & $43.71 \pm 10.11$ \\
\hline $7=\mathrm{HbAlc}$ & -0.048 & $-0.209 *$ & $-0.20 I^{*}$ & $-0.324 *$ & $-0.348 *$ & $-0.884^{*}$ & I & $7.25 \pm 1.05$ \\
\hline
\end{tabular}

Note: *Correlation is significant at the 0.05 level (two-tailed).

Table 3 Hierarchical Linear Regression of Self-Care Behaviors Onto Demographic Characteristics, $\mathrm{HL}$

\begin{tabular}{|l|l|l|l|l|}
\hline Step/Variables & $\begin{array}{l}\boldsymbol{\beta}^{* *} \\
\text { (Step I) }\end{array}$ & p-value* & $\begin{array}{l}\boldsymbol{\beta}^{* *} \\
\text { (Step 2) }\end{array}$ & p-value* \\
\hline $\begin{array}{l}\text { (I) Age groups } \\
\text { Gender }\end{array}$ & 0.031 & 0.658 & 0.069 & 0.312 \\
Job & 0.074 & 0.608 & 0.098 & 0.433 \\
Marital status & 0.070 & 0.633 & 0.157 & 0.224 \\
$\begin{array}{l}\text { (2) Reading health } \\
\text { information }\end{array}$ & 0.017 & 0.818 & 0.005 & 0.932 \\
$\begin{array}{l}\text { Ability to access } \\
\text { health information }\end{array}$ & & & 0.260 & 0.010 \\
$\begin{array}{l}\text { Understanding } \\
\text { health information }\end{array}$ & & & 0.042 & 0.714 \\
$\begin{array}{l}\text { Appraisal of health } \\
\text { information }\end{array}$ & & & 0.044 & 0.728 \\
$\begin{array}{l}\text { Decision-making } \\
R^{2}\end{array}$ & & & 0.277 & 0.008 \\
\hline
\end{tabular}

Notes: ${ }^{*}<0.05, * * \beta$ is standardized coefficient.

making ( $\mathrm{p}$-value $=0.001)$ were significant predictors of self-care behaviors $\mathrm{R} 2=0.288$, that is, approximately $28.8 \%$ of the variation in the self-care behaviors is explained by the HL and the demographic variables. Among the variables, decision-making was the strongest predictor of self-care behaviors.

We used Hierarchical multiple linear regression to predict of HbA1C. According to Table 4, in step 1, demographic variables were not significant predictors of $\mathrm{HbA1C}$ (p-value $<0.05, \mathrm{R} 2$ total $=0.002$ ). In step 2 , when the $\mathrm{HL}$ dimensions and self-care behaviors were included in the model, decision-making ( $\mathrm{p}$-value $=0.001)$, diet (p-value $<0.001$ ), exercise ( $p$-value $<0.001$ ) and medications ( $\mathrm{p}$-value $=0.013)$ were significant predictors of HbA1c $\mathrm{R} 2=$ 0.804 , that is, approximately $80.4 \%$ of the variation in the $\mathrm{HbA1c}$ is explained by the HL and the demographic variables. Among the variables, diet was the strongest predictor of HbAlc $(\beta=-0.679)$.
Table 4 Hierarchical Linear Regression of HbAlc Onto Demographic Characteristics, HL and Self-Care Behaviors

\begin{tabular}{|l|l|l|l|l|}
\hline Step/Variable & $\begin{array}{l}\beta^{* *} \\
\text { (Step I) }\end{array}$ & p-value* & $\begin{array}{l}\beta^{* *} \\
\text { (Step 2) }\end{array}$ & p-value* \\
\hline (I) Age groups & -0.002 & 0.975 & -0.035 & 0.342 \\
Gender & 0.084 & 0.565 & 0.054 & 0.435 \\
Job & 0.052 & 0.719 & 0.030 & 0.666 \\
Marital status & 0.001 & 0.991 & 0.003 & 0.930 \\
(2) Reading health & & & -0.029 & 0.641 \\
information & & & & \\
Ability to access & & & -0.020 & 0.755 \\
health information & & & & \\
Understanding & & & -0.007 & 0.921 \\
health information & & & & \\
Appraisal of health & & & -0.096 & 0.921 \\
information & & & & \\
Decision-making & & & 0.118 & 0.024 \\
Diet & & & -0.679 & 0.001 \\
Exercise & & & -0.379 & 0.001 \\
Glucose & & & 0.065 & 0.112 \\
monitoring & & & -0.088 & 0.013 \\
Medications & & & 0.804 & 0.001 \\
R & 0.002 & 0.980 & & \\
\hline
\end{tabular}

Notes: ${ }^{*}<<0.05,{ }^{* *} \beta$ is standardized coefficient.

\section{Discussion}

This study was conducted aiming at examining the influence of HL dimensions on self-care behaviors and $\mathrm{HbA1c}$ control among low education patients with T2DM in Sarab city, Iran. Having a good knowledge on self-care behaviors and identifying their influential factors may be helpful in addressing those factors through educational interventions.

The study results showed significant differences in HL by the patient's employment status. Similar with finding of the present study, Bohanny et $\mathrm{al}^{38}$ and Rafiezadeh et $\mathrm{al}^{39}$ reported that HL level was significantly higher in those who had a job compared to those who were unemployed. ${ }^{38}$ This could be because community outreach services and campaigns for diabetes screening often mostly target the 
working population because of their accessibility and leave out unemployed patients with diabetes. ${ }^{38}$ Such results indicate that health-care providers should focus on providing appropriate education to unemployed patients.

According to results of the present study, younger age is associated with possessing a higher level of HL. The results of similar studies confirm these findings. For example, Bohanny et $\mathrm{al}^{38}$ in the Marshall Islands and Schillinger et $\mathrm{al}^{30}$ in US among patients with T2DM indicated that older patients had lower HL. One of the possible reasons may be that older people have less cognitive ability, and this could have affected measurements of HL. Therefore, it is recommended that when designing educational interventions aiming at HL promotion the older people should be considered as a priority. Use of certain approaches such as picture and video with local language may be effective among this population.

In the present study, it was found that all HL dimensions, except reading health information, are positively associated with self-care behaviors. Furthermore, HL dimensions accounted for $28.8 \%$ of the total variation in self-care behaviors. The appraisal of health information and decision-making are important to influence the selfcare of patients with T2DM. However, the factor of decision-making was found to account for more total variation in the dimension of HL than the factor of appraisal of health information. This has also been found in previous studies. ${ }^{40,41}$ Pawlak considered the information technology to be one of the determinants of HL. ${ }^{42}$ Ease of gathering information would certainly increase the search for and gathering of information by respondents even further. The study conducted by Santosa ${ }^{43}$ showed that one factor affecting the HL is access to health information. It is vital that patients with diabetes have an understanding of the signs and symptoms of hypoglycemia, hyperglycemia, and how to properly self-administer medications correctly to manage diabetes. ${ }^{44}$ Understanding of the positive (positive history of hyperglycemia) and negative factors (sociodemographic variables) associated with diabetes HL is necessary for implementing preventive measures. ${ }^{45}$ In the study conducted by Pokhrel, those patients who had a better understanding of diabetic complications and their management showed fair glycemic control. ${ }^{46}$

In this study, decision-making was the strongest predictor of self-care behaviors $(\beta=0.451)$. Self-care decision making in chronic illness seems warranted so that the complexities inherent in this process can be more fully understood. ${ }^{47}$ Of course, compliance is considered as good decision making, and non-compliance is considered problematic decision-making. ${ }^{48}$ People with low literacy may face challenges in writing and communication, in particular, they are less likely to initiate and maintain successful diabetes care, which requires interactive communication and participatory decision-making. ${ }^{49}$ True self-care is a decision-making process requiring the cognitive ability to learn, perceive, interpret, reason, and respond. ${ }^{50}$

It is difficult to equate the results of this study directly with previous findings to comparison between these studies because of the use of various measures of health literacy. The study provides that the HL has negative significant correlation with the HbA1c levels, which is consistent with previous study conducted by Osborn et $\mathrm{al}^{51}$ in the US. However, another study conducted in the US found that the association between $\mathrm{HL}$ and the $\mathrm{HbAlc}$ levels was not significant. ${ }^{19}$ The relationship between HL and glycemic control may differ with patient populations and clinical settings. ${ }^{52}$ These findings indicated that to clarify the relationship, the studies require international comparisons between HL and glycemic control. Also, several observational studies found that HL is directly associated with self-care behaviors in diabetes patients, ${ }^{53,54}$ whereas some others observed no such direct association. ${ }^{38,55}$ These findings concluded that further studies are required to understand how HL is related to diabetes-related outcomes. However, some studies suggest that low HL contributes to lack of self-care knowledge and skills, ${ }^{56}$ lower rate of glycemic control $^{57}$ and higher HbAlc levels in diabetic sufferers. ${ }^{58}$

The results also support the strong negative relationship between self-care behaviors and $\mathrm{HbAlc}$ found in previous studies. ${ }^{32,59}$ Self-care behaviors together with HL dimensions explained $80.4 \%$ of the variance in HbAlc. Of the factors, diet and exercise are the most important factors associated with glycemic control. Therefore, strategies to improve patients' self-care behaviors especially healthy diet should be developed in the design of diabetic patients' education for controlling HbA1c among T2DM patients. Several studies found the protective association between adherence to the diet and improved diabetes control. ${ }^{60,61}$ Evidence from the European Prospective Investigation of Cancer and Nutrition (EPIC-Norfolk) study has shown that $1 \%$ increase in $\mathrm{HbAlc}$ level increased risk of death due to all causes by $28 \%{ }^{62}$

Another study result did not show a significant association between self-care activities and HbAlc. This may 
explain why health literacy is indirectly related (combined or separately as an individual component) through selfcare on A1c was not significant. ${ }^{63}$ Medication adherence could be a key factor impacting the relationship between health literacy and glycemic control. Moreover, there are other factors that could mediate the relationship between health literacy and health outcomes, including individuallevel factors, patient-provider interaction, as well as system-level factors. ${ }^{63}$ Brega et $\mathrm{al}^{64}$ demonstrated that the relationship between health literacy and glycemic control has been influenced by information about diabetes.

\section{Limitation}

Firstly, although present study suggests causal effect between variables, the cross-sectional design of the data precludes causal inference and can only refer to correlations at a single point in time between constructs observed. Secondly, majority of the participants were in age group 50 years and higher, an age in which people's cognitive status may be declined. The measurements in this study were self-reported and, thus, may not be perfect; nevertheless, self-reporting is the most common method for measuring psychosocial variables in primary care research. ${ }^{65}$ The potential social desirability bias must be considered, and the results must be cautiously interpreted. Also, another limitation in this study was lack of income data of the patients. Since majority of the patients did not answer the question of income level, the item excluded from analysis.

\section{Conclusion}

Our results suggest that the favorable effect of HL on the self-care behaviors may contribute to control of HbA1c among type 2 diabetes patients with low education. Therefore, the study highlights the importance of strengthening efforts to increase the level of HL across all patients with T2DM. Health-care professionals should be conscious that insufficient HL is correlated with poor selfcare behaviors and high $\mathrm{HbA} 1 \mathrm{c}$, which pose a barrier to effective care, and they should take this into consideration during all advices. Improving HL and promoting self-care behaviors would not only better the outcomes of diabetes but also it has economic benefits to the individual and the health system.

\section{Ethical Approval}

All procedures performed in this study were in accordance with the ethical standards of the institutional and/or national research committee and with the 1964 Helsinki Declaration and its later amendments or comparable ethical standards. Ethical approval to perform the study was obtained from the Ethics Committee in Sarab Faculty of Medical Sciences.

\section{Informed Consent}

Informed consent was obtained from all individual participants included in the study.

\section{Acknowledgments}

The authors wish to acknowledge Ms. Niloofar Kheiry, for critical editing of English grammar and syntax of the manuscript.

\section{Disclosure}

The authors declare that they have no competing interests.

\section{References}

1. Lozano R, Naghavi M, Foreman K, et al. Global and regional mortality from 235 causes of death for 20 age groups in 1990 and 2010 : a systematic analysis for the global burden of disease study 2010 . Lancet. 2012;380(9859):2095-2128. doi:10.1016/S0140-6736(12) 61728-0

2. World Health Organization. Diabetes: global report on diabetes. Available from: http://www.who.int/diabetes/global-report/en/. Accessed May 9, 2016.

3. Shaw JE, Sicree RA, Zimmet PZ. Global estimates of the prevalence of diabetes for 2010 and 2030. Diabetes Res Clin Pract. 2010;87 (1):4-14. doi:10.1016/j.diabres.2009.10.007

4. Centers for Disease Control and Prevention. National diabetes statistics report, 2020. Atlanta, GA: Centers for Disease Control and Prevention, US Department of Health and Human Services; 2020. Available from: https://www.cdc.gov/diabetes/data/statistics/statis tics-report.html. Accessed May 1, 2020.

5. Dahal PK, Hosseinzadeh H. Association of health literacy and diabetes self-management: a systematic review. Aust J Prim Health. 2020;25(6):526-533. doi:10.1071/PY19007

6. American Diabetes Association. Standards of medical care in diabetes-2012. Diabetes Care. 2012;35:S11. doi:10.2337/dc12-s011

7. American Diabetes Association. Standards of medical care in diabetes. Diabetes Care. 2010;2010(33):692.

8. Gebregziabher M, Egede LE, Lynch CP, Echols C, Zhao Y. Effect of trajectories of glycemic control on mortality in type 2 diabetes: a semiparametric joint modeling approach. Am J Epidemiol. 2010;171(10):1090-1098. doi:10.1093/aje/kwq070

9. Hirai FE, Moss SE, Klein BE, Klein R. Relationship of glycemic control, exogenous insulin, and C-peptide levels to ischemic heart disease mortality over a 16 -year period in people with older-onset diabetes: the Wisconsin Epidemiologic Study of Diabetic Retinopathy (WESDR). Diabetes Care. 2008;31(3):493-497. doi: $10.2337 / \mathrm{dc} 07-1161$

10. Norris SL, Lau J, Smith SJ, Schmid CH, Engelgau MM. Selfmanagement education for adults with type 2 diabetes: a meta-analysis of the effect on glycemic control. Diabetes Care. 2002;25(7):1159-1171. doi:10.2337/diacare.25.7.1159 
11. Panja S, Starr B, Colleran KM. Patient knowledge improves glycemic control: is it time to go back to the classroom? J Invest Med. 2005;53 (5):264-266. doi:10.2310/6650.2005.53509

12. Lawerence DB, Ragucci KR, Long LB, Parris BS, Helfer LA. Relationship of oral antihyperglycemic (sulfonylurea or metformin) medication adherence and hemoglobin A1c goal attainment for HMO patients enrolled in a diabetes disease management program. J Manage Care Pharm. 2006;12(6):466-471. doi:10.18553/jmcp.20 06.12.6.466

13. Reagan LA, Walsh SJ, Shelton D. Relationships of illness representation, diabetes knowledge, and self-care behaviour to glycemic control in incarcerated persons with diabetes. Int J Prison Health. 2016;12 (3):157-172. doi:10.1108/IJPH-04-2015-0010

14. Azizi M, Arsalani N, Mohammadi Shahboulaghi F, Hosseinzadeh S, Rajab A. The effect of self-care education on the control of diabetes complications, medications and $\mathrm{HbA1C}$ in adolescents with type 1 diabetes. J Hayat. 2017;22(4):350-361.

15. Surucu HA, Kizilci S, Ergor G. The impacts of diabetes education on self care agency, self-care activities and hbA1c levels of patients with type 2 diabetes: a randomized controlled study. Int J Caring Sci. 2017;10(1):479-489.

16. Wahowiak LK. National standards for diabetes self-management education and support: what's changed. AADE Pract. 2018;6 (1):20-24. doi:10.1177/2325160317742909

17. Le C, Rong S, Dingyun Y, Wenlong C. Socioeconomic disparities in type 2 diabetes mellitus prevalence and self-management behaviors in rural southwest China. Diabetes Res Clin Pract. 2016;121:9-16. doi:10.1016/j.diabres.2016.07.032

18. Wu D, Lam TP, Lam KF, Zhou XD, Sun KS. Public views towards community health and hospital-based outpatient services and their utilisation in Zhejiang, China: a mixed methods study. BMJ Open. 2017;7(11):e017611. doi:10.1136/bmjopen-2017-017611

19. Bains SS, Egede LE. Associations between health literacy, diabetes knowledge, self-care behaviors, and glycemic control in a low income population with type 2 diabetes. Diabetes Technol Ther. 2011;13(3):335-341. doi:10.1089/dia.2010.0160

20. World Heakth Organization. Health promotion: track 2: health literacy and health behaviour. Available from: https://www.who.int/ healthpromotion/conferences/7gchp/track2/en/. Accessed April 8, 2020.

21. Wang R-H, Hsu H-C, Lee Y-J, Shin S-J, Lin K-D, An L-W. Patient empowerment interacts with health literacy to associate with subsequent self-management behaviors in patients with type 2 diabetes: a prospective study in Taiwan. Patient Educ Couns. 2016;99 (10):1626-1631. doi:10.1016/j.pec.2016.04.001

22. Bagnasco A, Di Giacomo P, Da Rin Della Mora R, et al. Factors influencing self-management in patients with type 2 diabetes: a quantitative systematic review protocol. J Adv Nurs. 2014;70 (1):187-200. doi:10.1111/jan.12178

23. Saeed H, Saleem Z, Naeem R, Shahzadi I, Islam M. Impact of health literacy on diabetes outcomes: a cross-sectional study from Lahore, Pakistan. Public Health. 2018;156:8-14. doi:10.1016/j.puhe.2017. 12.005

24. Davis TC, Wolf MS, Bass PF, et al. Low literacy impairs comprehension of prescription drug warning labels. J Gen Intern Med. 2006;21 (8):847-851. doi:10.1111/j.1525-1497.2006.00529.x

25. Lindau ST, Basu A, Leitsch SA. Health literacy as a predictor of follow-up after an abnormal pap smear. J Gen Intern Med. 2006;21 (8):829-834. doi:10.1111/j.1525-1497.2006.00534.x

26. Schillinger D, Grumbach K, Piette J, Wang F, Osmond D, Daher C. Association of health literacy with diabetes outcomes. JAMA. 2002;288(4):475-482. doi:10.1001/jama.288.4.475

27. Powell CK, Hill EG, Clancy DE. The relationship between health literacy and diabetes knowledge and readiness to take health actions. Diabetes Educ. 2007;33(1):144-151. doi:10.1177/0145721706297 452
28. Morris NS, MacLean CD, Littenberg B. Literacy and health outcomes: a cross-sectional study in 1002 adults with diabetes. $B M C$ Fam Pract. 2006;7(1):49. doi:10.1186/1471-2296-7-49

29. Berkman ND, Sheridan SL, Donahue KE, et al. Health literacy interventions and outcomes: an updated systematic review. Evid Rep Technol Assess (Full Rep). 2011;199(1):941.

30. Schillinger D, Barton LR, Karter AJ, Wang F, Adler N. Does literacy mediate the relationship between education and health outcomes? A study of a low-income population with diabetes. Public Health Rep. 2006;121(3):245-254. doi:10.1177/003335490612100305

31. Osborn CY, Cavanaugh K, Wallston KA, Rothman RL. Self-efficacy links health literacy and numeracy to glycemic control. J Health Commun. 2010;15(S2):146-158. doi:10.1080/10810730.2010.499980

32. Lee Y-J, Shin S-J, Wang R-H, Lin K-D, Lee Y-L, Wang Y-H. Pathways of empowerment perceptions, health literacy, self-efficacy, and self-care behaviors to glycemic control in patients with type 2 diabetes mellitus. Patient Educ Couns. 2016;99(2):287-294. doi:10. 1016/j.pec.2015.08.021

33. Sarbazi E, Moradi F, Ghaffari-Fam S, Mirzaeian K, Babazadeh T. Cognitive predictors of physical activity behaviors among rural patients with type 2 diabetes: applicability of the Extended Theory of Reasoned Action (ETRA). J Multidiscip Healthc. 2019;12:429. doi:10.2147/JMDH.S198964

34. Montazeri A, Tavousi M, Rakhshani F, et al. Health Literacy for Iranian Adults (HELIA): development and psychometric properties. Payesh. 2014;13(5):589-599.

35. Toobert DJ, Hampson SE, Glasgow RE. The summary of diabetes self-care activities measure: results from 7 studies and a revised scale. Diabetes Care. 2000;23(7):943-950. doi:10.2337/diacare.23.7.943

36. Didarloo A, Shojaeizadeh D, Asl RG, Habibzadeh H, Niknami S, Pourali R. Prediction of self-management behavior among Iranian women with type 2 diabetes: application of the theory of reasoned action along with self-efficacy (ETRA). Iran Red Crescent Med J. 2012;14(2):86.

37. Marathe PH, Gao HX, Close KL. American Diabetes Association Standards of Medical Care in Diabetes 2017. J Diabetes. 2017;9 (4):320-324. doi:10.1111/1753-0407.12524

38. Bohanny W, Wu SFV, Liu CY, Yeh SH, Tsay SL, Wang TJ. Health literacy, self-efficacy, and self-care behaviors in patients with type 2 diabetes mellitus. J Am Assoc Nurse Pract. 2013;25(9):495-502. doi:10.1111/1745-7599.12017

39. Rafiezadeh GS, Tabarsy B, Hassanjani S, Razavi M, Amjady M, Hojjati H. Relationship Between the Health Literacy with Selfefficacy of the Diabetic Patient's Type 2 Referred to Gorgan City Clinic in 2014. J Diabetes Nurs. 2015;3(2);30-42.

40. Masoompour M, Tirgari B, Ghazanfari Z. The relationship between health literacy, self-efficacy, and self-care behaviors in diabetic patients. Evid Based Care. 2017;7(3):17-25.

41. Tahery N. The association of health literacy with self-efficacy and self-care, in type 2 diabetes patients. Iran J Endocrinol Metab. 2018;20(3):135-141.

42. Pawlak R. Economic considerations of health literacy. Nurs Econ. 2005;23(4):173.

43. Santosa KS. Faktor-Faktor yang Berhubungan dengan Tingkat Kemelekan Kesehatan Pasien di Klinik Dokter Keluarga Fakultas Kedokteran Universitas Indonesia Kiara, DKI Jakarta Tahun. DKI Jakarta: Universitas Indonesia Kiara; 2012.

44. Shakibazadeh E, Rashidian A, Larijani B, Shojaeezadeh D, Forouzanfar M, Karimi Shahanjarini A. Perceived barriers and self-efficacy: impact on self-care behaviors in adults with type 2 diabetes. J Hayat. 2010;15(4):69-78.

45. Raffensperger S, Kuczmarski MF, Hotchkiss L, Cotugna N, Evans MK, Zonderman AB. Effect of race and predictors of socioeconomic status on diet quality in the HANDLS study sample. J Natl Med Assoc. 2010;102(10):923-930. doi:10.1016/S0027-9684(15)30 $711-2$ 
46. Pokhrel S, Shrestha S, Timilsina A, Sapkota M, Bhatt MP, Pardhe BD. Self-care adherence and barriers to good glycaemic control in Nepalese type 2 diabetes mellitus patients: a hospital-based cross-sectional study. $J$ Multidiscip Healthc. 2019;12:817. doi:10.2147/JMDH.S216842

47. Thorne S, Paterson B, Russell C, Schultz A. Complementary/alternative medicine in chronic illness as informed self-care decision making. Int J Nurs Stud. 2002;39(7):671-683. doi:10.1016/S00207489(02)00005-6

48. Hess DJ. The ethics of compliance: a dialectic. Adv Nurs Sci. 1996;19 (1):18-27. doi:10.1097/00012272-199609000-00004

49. Suka M, Odajima T, Okamoto M, et al. Relationship between health literacy, health information access, health behavior, and health status in Japanese people. Patient Educ Couns. 2015;98(5):660-668. doi:10.1016/j.pec.2015.02.013

50. Dickson VV, Tkacs N, Riegel B. Cognitive influences on self-care decision making in persons with heart failure. Am Heart J. 2007;154 (3):424-431. doi:10.1016/j.ahj.2007.04.058

51. Osborne RH, Batterham RW, Elsworth GR, Hawkins M, Buchbinder R. The grounded psychometric development and initial validation of the Health Literacy Questionnaire (HLQ). BMC Public Health. 2013;13(1):658. doi:10.1186/1471-2458-13-658

52. Bailey SC, Brega AG, Crutchfield TM, et al. Update on health literacy and diabetes. Diabetes Educ. 2014;40(5):581-604. doi:10.1177/0145721714540220

53. Lee E-H, Lee YW, Moon SH. A structural equation model linking health literacy to self-efficacy, self-care activities, and health-related quality of life in patients with type 2 diabetes. Asian Nurs Res. 2016;10(1):82-87. doi:10.1016/j.anr.2016.01.005

54. Reisi M, Mostafavi F, Javadzade H, Mahaki B, Tavassoli E, Sharifirad G. Impact of health literacy, self-efficacy, and outcome expectations on adherence to self-care behaviors in Iranians with type 2 diabetes. Oman Med J. 2016;31(1):52. doi:10.5001/omj.2016.10

55. Eyüboğlu E, Schulz PJ. Do health literacy and patient empowerment affect self-care behaviour? A survey study among Turkish patients with diabetes. BMJ Open. 2016;6(3):e010186. doi:10.1136/bmjopen2015-010186

56. van der Heide I, Uiters E, Rademakers J, Struijs JN, Schuit AJ, Baan CA. Associations among health literacy, diabetes knowledge, and self-management behavior in adults with diabetes: results of a dutch cross-sectional study. $J$ Health Commun. 2014;19 (sup2):115-131. doi:10.1080/10810730.2014.936989
57. Al Sayah F, Majumdar SR, Johnson JA. Association of inadequate health literacy with health outcomes in patients with type 2 diabetes and depression: secondary analysis of a controlled trial. Can J Diabetes. 2015;39(4):259-265. doi:10.1016/j.jcjd.2014.11.005

58. Souza JG, Apolinario D, Magaldi RM, Busse AL, Campora F, JacobFilho W. Functional health literacy and glycaemic control in older adults with type 2 diabetes: a cross-sectional study. BMJ Open. 2014;4(2):e004180. doi:10.1136/bmjopen-2013-004180

59. Yarmohammadi S, Momenyan S, Ghaffari M, Ali R, Azizpour M. Impact of functional, communicative and critical health literacy on glycemic control among patients with type 2 diabetes, and the mediating role of self-care. Psychol Res Behav Manag. 2019;12:427. doi:10.2147/PRBM.S207466

60. Esposito K, Maiorino M, Di Palo C, Giugliano D, Group CPHS. Adherence to a mediterranean diet and glycaemic control in type 2 diabetes mellitus. Diabet Med. 2009;26(9):900-907. doi:10.1111/ j.1464-5491.2009.02798.x

61. Díez-Espino J, Buil-Cosiales P, Serrano-Martínez M, Toledo E, Salas-Salvadó J, Martínez-González MÁ. Adherence to the mediterranean diet in patients with type 2 diabetes mellitus and HbA1c level. Ann Nutr Metab. 2011;58(1):74-78. doi:10.1159/000324718

62. Khaw K-T, Wareham N, Luben R, et al. Glycated haemoglobin, diabetes, and mortality in men in Norfolk cohort of European Prospective Investigation of Cancer and Nutrition (EPIC-Norfolk). BMJ. 2001;322(7277):15. doi:10.1136/bmj.322.7277.15

63. Luo H, Patil SP, Cummings DM, Bell RA, Wu Q, Adams AD. Health literacy, self-management activities, and glycemic control among adults with type 2 diabetes: a path analysis. J Public Health Manage Pract. 2020;26(3):280-286. doi:10.1097/PHH.0000000000000984

64. Brega AG, Ang A, Vega W, et al. Mechanisms underlying the relationship between health literacy and glycemic control in American Indians and Alaska Natives. Patient Educ Couns. 2012;88(1):61-68. doi:10.1016/j.pec.2012.03.008

65. Glasgow RE, Ory MG, Klesges LM, Cifuentes M, Fernald DH, Green LA. Practical and relevant self-report measures of patient health behaviors for primary care research. Ann Fam Med. 2005;3 (1):73-81. doi:10.1370/afm.261

Diabetes, Metabolic Syndrome and Obesity: Targets and Therapy

Dovepress

\section{Publish your work in this journal}

Diabetes, Metabolic Syndrome and Obesity: Targets and Therapy is an international, peer-reviewed open-access journal committed to the rapid publication of the latest laboratory and clinical findings in the fields of diabetes, metabolic syndrome and obesity research. Original research, review, case reports, hypothesis formation, expert opinion and commentaries are all considered for publication. The manuscript management system is completely online and includes a very quick and fair peer-review system, which is all easy to use. Visit http://www.dovepress.com/testimonials.php to read real quotes from published authors. 